declared, Bahar Keleşoğlu: None declared, Sedat Yılmaz: None declared, Yavuz Pehlivan: None declared, Ender Terzioğlu: None declared, Levent Kılıç: None declared, Sukran Erten: None declared, Koray Taşçılar: None declared, Umut Kalyoncu Grant/research support from: MSD, Roche, UCB, Novartis and Pfizer, Consultant for: MSD, Abbvie, Roche, UCB, Novartis, Pfizer and Abdi Ibrahim, Speakers bureau: MSD, Abbvie, Roche, UCB, Novartis, Pfizer and Abdi Ibrahim

DOI: 10.1136/annrheumdis-2019-eular.5888

\section{AB0724 DOSE PREGNANCY AND VAGINAL DELIVERY WORSEN ANKYLOSING SPONDYLITIS?}

Jung Sun Lee ${ }^{1}$, Ji Seon Oh${ }^{1}$, Wook Jang Seo ${ }^{2}$, Seokchan Hong ${ }^{1}$, Yong-Gil Kim ${ }^{1}$ Chang-Keun Lee ${ }^{1}$, Bin Yoo ${ }^{1} .{ }^{1}$ University of Ulsan College of Medicine, Asan Medical Center, Seoul, Korea, Rep. of (South Korea); ${ }^{2}$ Veterans Health Service Medical Center, Seoul, Korea, Rep. of (South Korea)

Background Ankylosing spondylitis (AS) affects the sacroiliac joints and commonly occurs in those at the reproductive age. Women with AS have a higher rate of cesarean section (CS) compared with healthy controls.

Objectives This study determined the effect of pregnancy and delivery methods on AS worsening by analyzing prescription pattern.

Methods Based on the Korean Health Insurance Review and Assessment Service claims database, subjects comprised female patients aged 20-49 years with an AS. Alteration of prescriptions was defined by changing the at two time periods of 1-2 years pre-delivery and 1-year post-delivery. We compared alteration of prescriptions between AS patients with delivery and 1:1 matched AS patients without delivery. In addition, among AS patients with delivery, alteration of prescriptions according to delivery method was evaluated.

Results Among 6,821 female patients with AS, 996 patients in the delivery group were younger, had a higher proportion of non-drug use, and had lower rates of comorbidity than the no delivery group. The alteration of prescriptions did not differ between the AS with delivery and the AS without delivery groups (OR 0.76, 95\% $\mathrm{Cl}$ 0.56-1.05). Furthermore, the overall alteration of prescriptions did not differ significantly between vaginal delivery (VD) and CS (OR 0.72, 95\% CI 0.45-1.14). Conclusion The rate of alteration of prescriptions was comparable between the AS patients with and without delivery. There was no association between VD and alteration of prescriptions compared with CS. Taken together, pregnancy and VD may not be assumed to be factors of AS worsening.

Disclosure of Interests None declared

DOI: 10.1136/annrheumdis-2019-eular.2519

\section{AB0725 $\quad$ ASSOCIATION BETWEEN RADIOGRAPHIC PROGRESSION AND CARDIOVASCULAR RISK IN SPONDYLOARTHRITIS: DATA FROM COSPAR REGISTRY}

Ladehesa Pineda Lourdes ${ }^{1}$, Gómez García Ignacio ${ }^{2}$, María del Carmen Castro Villegas $^{2}$, Pedro Seguí Azpilcueta ${ }^{3}$, Maria del Carmen Abalos-Aguilera ${ }^{4}$, Bautista Aguilar Laura $^{2}$, Inmaculada Concepcion Aranda-Valera ${ }^{5}$, Rocio Segura ${ }^{5}$, Rafaela Ortega Castro $^{5}$, Clementina López-Medina ${ }^{6}$, Pérez Sánchez Laura ${ }^{7}$, Puche Larrubia Maria Ángeles ${ }^{5}$, Chary Lopez-Pedrera ${ }^{4}$,Font Ugalde Pilar ${ }^{5}$, Garrido Castro Juan Luis ${ }^{6}$, Alejandro Escudero Contreras ${ }^{5}$, Eduardo Collantes Estevez ${ }^{5}$ Jiménez Gómez Yolanda ${ }^{4}$, COSPAR Study Group. ${ }^{1}$ Universitary Hospital Reina Sofia, Rheumatology, Córdoba, Spain; ${ }^{2}$ Reina Sofía University Hospital/IMIBIC/ University of Cordoba, Rheumatology, Cordoba, Spain; ${ }^{3}$ Reina Sofía University Hospital/IMIBIC/University of Cordoba, Radiology, Córdoba, Spain; ${ }^{4} I M I B I C$, Córdoba, Spain; ${ }^{5}$ Reina Sofía University Hospital/IMIBIC/University of Cordoba, Rheumatology, Córdoba, Spain; ${ }^{6}$ University of Córdoba, Córdoba, Spain; ${ }^{7}$ Reina Sofía University Hospital/IMIBIC/University of Cordoba, Rheumaology, Córdoba, Spain

Background: Studies suggest that radiographic damage is associated with cardiovascular (CV) risk in axial spondyloarthritis (axSpA). However, the relationship among disease characteristics directly related to structural damage and CV risk has not yet been fully clarified.

Objectives: To analyze the association of structural damage with the presence of atherosclerotic plaques via carotid ultrasound (US) and the increased CV risk in a registry of patients with $\mathrm{SpA}$.

Methods: Eighty-five patients with $\mathrm{SpA}$ (ASAS criteria) from the $\mathrm{SpA}$ registry from Cordoba (CoSpaR) were selected for a cross-sectional study and underwent a complete clinical history, physical examination and biochemical analysis. Variables about demographics, clinical parameters and CV risk factors were collected. CV risk was evaluated by estimating SCORE index and assessing presence of atherosclerotic plaques through carotid US performed by a qualified radiologist. Independent-samples t test was used to evaluate the association between radiological characteristics and presence of atherosclerosis. Multiple lineal regression (MLR) was performed to assess the variables potentially associated with increased SCORE. All comparisons were bilateral.

Results: Baseline characteristics are shown in the table. Values are mean $\pm S D$ for quantitative and $N(\%)$ for qualitative variables. Regarding characteristics related with radiographic damage and CV risk, they exhibited a mSASSS of $14.84 \pm 18.4(7.27 \pm 9.64$ in cervical spine and 7.72 \pm 10.14 in lumbar spine). Average $\mathrm{BMl} 26.88 \pm 4.13,33(38.8 \%)$ were smokers, $16(18.8 \%)$ had diagnosis of arterial hypertension, $1(1.2 \%)$ of diabetes mellitus, $13(15.3 \%)$ of hyperlipidemia, and $8(9.4 \%)$ took lipid lowering drugs. Examination with carotid US found that 14 (16.5\%) patients had previously unknown atherosclerotic plaques. After classification according to SCORE index, 60 (76.9\%) had low CV risk, $10(12.8 \%)$ moderate, and both high and very high CV risk categories had $4(5.1 \%)$ patients each.

In patients with atherosclerotic plaques, age, disease duration and varia bles related to radiographic damage (mSASSS [total, cervical and lumbar] and bone bridges) were significantly higher $(\mathrm{p}<0.05)$. In addition, mSASSS in cervical spine $(p=0.063)$ and age $(p<0.001)$ were associated with the SCORE and were predictors of increased CV risk in MLR analysis.

\begin{tabular}{lc}
\hline Age (years) $(\mathrm{N}=85)$ & $44.5 \pm 12.2$ \\
\hline Sex (males) $(\mathrm{N}=85)$ & $59(69.4)$ \\
HLA B27 $(\mathrm{N}=83)$ & $71(83.5)$ \\
axSpA $(\mathrm{N}=85)$ & $79(92.9)$ \\
Radiographic axSpA $(\mathrm{N}=77)$ & $63(74.1)$ \\
BMI $\left(\mathrm{kg} / \mathrm{m}^{2}\right)(\mathrm{N}=80)$ & $26,9 \pm 4.13$ \\
Disease duration (years) $(\mathrm{N}=82)$ & $18.01 \pm 13.62$ \\
Smokers $(\mathrm{N}=84)$ & $33(38.8)$ \\
ASDAS-CRP & $3.13 \pm 1.05$ \\
ASAS HI $(\mathrm{N}=82)$ & $4.05 \pm 3.8$ \\
\hline
\end{tabular}

Conclusion: Presence of atherosclerosis is associated with age, disease duration and radiographic damage in SpA. Age and structural damage especially in the cervical spine predicted a greater CV risk. Thus, it is important to identify these patients in order to maintain tight control and avoid development of CV disease.

Acknowledgement: Funded by: JA PI-0139-2017

Disclosure of Interests: Ladehesa Pineda Lourdes: None declared, Gómez García Ignacio: None declared, María del Carmen Castro Villegas Paid instructor for: MSD, Abbvie, Pfizer, Janssen, Lilly, Roche, Pedro Seguí Azpilcueta: None declared, Maria del Carmen AbalosAguilera: None declared, Bautista Aguilar Laura: None declared, Inmaculada Concepcion Aranda-Valera: None declared, Rocio Segura: None declared, Rafaela Ortega Castro: None declared, Clementina López-Medina: None declared, Pérez Sánchez Laura: None declared, Puche Larrubia Maria Ángeles: None declared, Chary Lopez-Pedrera: None declared, Font Ugalde Pilar: None declared, Garrido Castro Juan Luis: None declared, Alejandro Escudero Contreras: None declared, Eduardo Collantes Estevez: None declared, Jiménez Gómez Yolanda: None declared

DOI: 10.1136/annrheumdis-2019-eular.6050

\section{AB0726 WHAT IS THE IMPACT OF MRI ON THE PERFORMANCE OF THE ASAS CLASSIFICATION CRITERIA IN PATIENTS PRESENTING WITH UNDIAGNOSED BACK PAIN?}

${ }^{1,2}$ Walter P. Maksymowych, Raj Carmona ${ }^{3}$, James Yeung ${ }^{4}$, Jon Chan ${ }^{5}$, Liam Martin $^{6}$, Sibel Aydin ${ }^{7}$, Dianne Mosher ${ }^{6}$, Ariel Masetto ${ }^{8}$, Stephanie Keeling ${ }^{1}$, Olga Ziouzina ${ }^{6}$, Sherry Rohekar ${ }^{9}$, Joel Paschke ${ }^{2}$, Amanda Carapellucci $^{2}$, Robert G. Lambert'. ' University of Alberta, Edmonton, Canada; ${ }^{2} \mathrm{CaRE}$ Arthritis, Edmonton, Canada; ${ }^{3}$ McMaster University, Hamilton, Canada; ${ }^{4}$ James Yeung Rheumatology, Vancouver, Canada; ${ }^{5}$ Artus Health Center, Vancouver, Canada; ${ }^{6}$ University of Calgary, Calgary, Canada; ${ }^{7}$ University of Ottawa, Ottawa, Canada; ${ }^{8}$ University of Sherbrooke, Sherbrooke, Canada; ${ }^{9}$ Lawson Health Research Institute, London, Canada

Background: Several cohorts have reported the performance of the ASAS classification criteria in settings where clinical, radiographic, and MRI features have been simultaneously incorporated into the diagnostic evaluation in arriving at a gold standard for the testing of the criteria MRI improves diagnostic precision but access is limited and it is therefore still important to understand how the criteria perform in a setting where diagnostic evaluation can be conducted sequentially before and after MRI assessment. We hypothesized that the ASAS criteria would demonstrate enhanced specificity when MRI is available due to enhanced diagnostic precision. 